\title{
Avanços e Barreiras ao Fornecimento Enxuto da Indústria Automobilística Brasileira: a Perspectiva dos Fornecedores
}

\author{
Rebecca Arkader
}

\section{RESUMO}

Este trabalho, a partir de abrangente pesquisa de estudo de casos, conduzida na indústria automobilística brasileira, trata da perspectiva das empresas fornecedoras de autopeças no contexto dos novos relacionamentos entre compradores e fornecedores industriais decorrentes das práticas da produção enxuta. Por um lado, os fornecedores identificaram a existência de avanços nas relações de fornecimento, no que diz respeito a questões operacionais. Por outro, perceberam menor avanço quanto a questões estratégicas. Os fornecedores observaram ainda a existência de barreiras aos avanços, tanto de natureza organizacional quanto de natureza ambiental, estas originando-se nas peculiaridades do ambiente econômico e de negócios local. Tais resultados são discutidos à luz da perspectiva dos compradores (as montadoras), também levantada na pesquisa, levando à identificação de elementos para a formulação de uma explicação para a trajetória das relações entre compradores e fornecedores na indústria automobilística brasileira.

Palavras-chaves: relacionamento entre compradores e fornecedores; gerência de fornecimento; indústria automobilística brasileira.

\begin{abstract}
This paper deals with the perspective of autoparts suppliers in Brazilian automotive industry in the context of the renewed buyer-supplier relationships under lean production practices, based on a comprehensive case study research. The suppliers perceived advances in relationships as far as operational issues were concerned. On the other hand, they saw less advances in terms of strategic issues. The suppliers also identified both organizational, firm-specific barriers and environmental barriers originated in the peculiarities of local economic and business environment. These results are discussed in view of the perspective of buyers (the assemblers) uncovered in the same research, leading to the identification of elements to formulate an explanation for the path of buyer-supplier relations in Brazilian automotive industry.
\end{abstract}

Key words: buyer-supplier relationships; supply management; brazilian automotive industry. 


\section{INTRODUÇÃO}

O relacionamento entre compradores e fornecedores industriais (buyer-supplier relationships) tem sido objeto, ao longo dos últimos anos, de grande interesse para pesquisadores em operações e outras áreas gerenciais. A crescente adoção das práticas de produção enxuta em diversos setores industriais, especialmente na indústria automobilística, tem conduzido as empresas na direção de novos padrões de relações de fornecimento que, em seu conjunto, vêm sendo chamados de fornecimento enxuto (Womack, Jones e Ross, 1991). O fornecimento enxuto é uma abordagem do relacionamento entre compradores e fornecedores em uma perspectiva de longo prazo, em que se gerenciam relacionamentos (e não transações episódicas), para evitar desperdícios e adicionar valor (Lamming, 1993). Uma das principais características do conceito é, talvez, a interdependência que se estabelece entre compradores e fornecedores, a exemplo do modelo adotado pela indústria japonesa (Womack, Jones e Ross, 1991).

As características e os impactos trazidos pelas novas práticas de fornecimento têm sido apresentados em uma série de trabalhos que lidam com os antigos e novos padrões de relações contratuais, ou seja, aqueles da produção em massa e aqueles da produção enxuta (entre outros, Nishiguchi, 1989; Womack, Jones e Ross, 1991; Sako, 1992; Dyer e Ouchi, 1993; Lamming, 1993; Macbeth e Ferguson, 1994; Hines, 1996). As mudanças incluem nova visão para a negociação das condições de fornecimento, maior horizonte contratual, reestruturação das bases de fornecedores por meio de processos sistemáticos de escolha e desenvolvimento e pela sua organização em uma configuração piramidal, com redução do número de fornecedores por peça e novas abordagens quanto à entrega, qualidade, envolvimento em projeto e troca de informações. O novo modelo de relacionamento entre compradores e fornecedores tem sido rotulado como sendo de parceria (Lamming, 1993; Dyer e Ouchi, 1993; Ellram e Edis, 1996), em que prevaleceria a confiança entre as partes.

Apesar deste grande interesse despertado pela questão dos relacionamentos entre compradores e fornecedores no âmbito das práticas de produção enxuta, a maior parte das pesquisas existentes tem privilegiado, talvez por tradição, a perspectiva dos compradores. A abordagem dos relacionamentos entre compradores e fornecedores na literatura de compras ou de marketing industrial tem apontado para uma tendência entre os compradores a identificarem apenas vantagens na adoção das novas relações de fornecimento (Lyons, Krachenberg e Henke Jr., 1990; Leavy, 1994). Uma criteriosa revisão da literatura sobre a renovação das 
bases de relacionamento entre compradores e fornecedores (Arkader, 1997) revelou um número ainda comparativamente reduzido de contribuições, que apresentam e discutem a perspectiva dos fornecedores. Nestas há indicações de que os fornecedores, de modo geral, não estariam compartilhando a visão otimista, quanto aos relacionamentos, que estão expressando os compradores. Mais limitado ainda tem sido o número de contribuições na literatura sobre o relacionamento entre compradores e fornecedores em países em desenvolvimento. Considerando-se o escopo cada vez mais global das operações de manufatura em geral, e da indústria automotiva em particular, essa questão específica merece ser estudada.

Este artigo trata da perspectiva dos fornecedores na indústria automotiva brasileira quanto aos avanços e barreiras nas novas relações entre compradores e fornecedores no contexto das práticas de produção enxuta, ou seja, as relações de fornecimento enxuto. $\mathrm{O}$ trabalho inicia-se com breve revisão da abordagem da perspectiva dos fornecedores na literatura internacional, bem como do possível hiato entre as percepções de compradores e fornecedores quanto ao estágio dos relacionamentos. Logo após é apresentado o pano-de-fundo conceitual que serviu de base à pesquisa. É indicada, a seguir, a metodologia adotada para o estudo de campo. O trabalho prossegue com a apresentação e discussão dos resultados da pesquisa, no que diz respeito às percepções dos fornecedores quanto aos avanços e barreiras do fornecimento enxuto. Em conclusão, o artigo relaciona os resultados da perspectiva dos fornecedores com aqueles sobre a perspectiva dos compradores, levantada em pesquisa complementar, e identifica os elementos para se formular uma explicação para a trajetória das relações de fornecimento na indústria automobilística brasileira.

\section{A Perspectiva dos Fornecedores no Estudo das Relações entre COMPRADORES E FORNECEDORES}

As indicações na literatura são de que a perspectiva dos fornecedores, quanto aos novos padrões de relacionamento entre compradores e fornecedores, não corresponde àquela dos compradores e, em geral, não estaria apontando para um jogo ganha-ganha (Womack, Jones e Ross, 1991; Helper, 1991, 1994; Lamming, 1993; Turnbull et al., 1993; Karlsson and Norr, 1994; Purdy, Astad e Safayeni, 1994). De acordo com essa perspectiva, os compradores estariam tirando proveito de seu poder de barganha mais elevado no relacionamento, para imporem práticas enxutas a seus fornecedores, às custas da rentabilidade desses últimos (Helper,1994).

As pesquisas de Helper (1991, 1994) sobre a perspectiva dos fornecedores fo- 
ram focadas principalmente no lado fornecedor da indústria automotiva americana, buscando estabelecer vínculos entre as práticas vigentes no relacionamento entre compradores e fornecedores e o desempenho das empresas. Apesar de alguma melhoria relatada pelos fornecedores em seu relacionamento com os clientes, os primeiros não percebiam um comprometimento maior por parte dos últimos e, em geral, não estavam convencidos da eficácia dos programas de melhoria da qualidade ou de entregas just-in-time. Essas, de fato, eram vistas principalmente como forma de transferir estoque dos compradores para os fornecedores. Tais estudos longitudinais levaram a autora à conclusão de que as relações de fornecimento estavam "em uma encruzilhada" (Helper, 1994, p. 638), devido à acomodação entre as pressões para a redução de custos no curto prazo e a meta de competitividade no longo prazo.

Turnbull et al. (1993), investigando os fornecedores de autopeças no País de Gales, observaram que estes percebiam mudanças em seus relacionamentos com os clientes; no entanto, estas estariam beneficiando antes de tudo os compradores, especialmente no que diz respeito à imposição de entregas just-in-time.

A literatura traz indicações de que haveria um hiato nas percepções quanto à existência de parceria efetiva nos novos relacionamentos. Burnes e New (1996, p. 21) constataram uma tendência na direção de se ver "tudo azul" (rose tinted glasses) na questão da situação dos relacionamentos entre compradores e fornecedores no Reino Unido. Segundo esses autores,

"apesar do fato de que órgãos oficiais, companhias líderes e a literatura concordariam amplamente com [essa conceituação de parceria], a realidade parece ser diferente da retórica. Isto se mostrou em um dos resultados da pesquisa que desenvolvemos com a A.T. Kearney [1994] que revelou que o termo 'parceria' era usado de uma vasta variedade de formas, muitas vezes com conotações irônicas. Para alguns, parceria simplesmente significava descontos nos preços para clientes favorecidos; para outros, acordos complexos de compartilhamento de risco e resultados para novos produtos. Em alguns casos, a linguagem de parceria parecia ser usada para desinfetar o uso brutal de poder comercial. Essa visão vem ao encontro das constatações de Lamming: as iniciativas de parceria são muitas vezes mais "retórica do que realidade"" (Burnes e New, 1996, p. 22).

Lamming (apud DTI/SMMT, 1994, p. 6), de fato, em relatório elaborado para a análise da indústria automobilística do Reino Unido, identificou um hiato entre o que as empresas dizem estar praticando e a realidade: "Muitos dos conceitos de políticas e opções de estratégia discutidas em relatórios e artigos e, muitas vezes professados por executivos de compras dos fabricantes de veículos, ainda estão 
por se tornar realidade. Os fornecedores ainda estão desconfiados da retórica de seus clientes, ao mesmo tempo que os fabricantes de veículos manifestam privada e publicamente a insatisfação com o desempenho de seus fornecedores de componentes". O relatório aponta que as montadoras tipicamente alegam estar caminhando na direção da implementação de novos padrões de relacionamento (por exemplo, Qualidade Total, JIT, desenvolvimento de fornecedores), mas que seus fornecedores não identificam na prática a sua adoção, ou registram seu uso de maneira adversária, ou contraproducente.

Apesar do número relativamente reduzido de estudos dedicados ao assunto, pode-se encontrar algumas indicações na literatura com relação a entraves à adoção de práticas de fornecimento enxuto. Uma provável barreira seria o histórico de negociações adversárias, que possivelmente poderia interferir com o estabelecimento de relacionamentos de confiança entre compradores e fornecedores (Stuart e McCutcheon, 1995). Outra poderia estar na estrutura da própria indústria, em termos da contradição de se ter de alcançar uma escala adequada e boa capacitação (e portanto ter à disposição os recursos exigidos por tais objetivos) e a tendência ao estabelecimento de relacionamentos dedicados ao fornecimento (Turnbull, Oliver e Wilkinson, 1992). De fato, nesse último caso, poderia haver falta de compatibilidade entre as exigências de uma estratégia colaborativa e a estrutura da indústria tomada como contexto.

\section{O Quadro Conceitual da Pesquisa}

A literatura sobre relacionamentos entre compradores e fornecedores aponta a existência de dois conjuntos extremos de práticas ou características que podem ajudar a situar relacionamentos específicos em termos de seu avanço em direção a uma colaboração mais forte e a condições de fornecimento enxuto. Rotulados de modelos tradicional e de fornecimento enxuto ou de parceria, esses conjuntos, incorporando as múltiplas contribuições da literatura (vide Arkader, 1997), sintetizam o paradigma antigo e novo na área de relações de fornecimento, como se segue. 


\begin{tabular}{|c|c|c|}
\hline \multirow[b]{2}{*}{$\begin{array}{l}\text { PRÁTICAS E } \\
\text { CARACTERÍSTICAS }\end{array}$} & \multicolumn{2}{|c|}{ MODELO } \\
\hline & Tradicional & $\begin{array}{c}\text { Fornecimento Enxuto ou } \\
\text { Parceria }\end{array}$ \\
\hline $\begin{array}{l}\text { Padrões de Negociação e } \\
\text { Relacionamento }\end{array}$ & $\begin{array}{l}\text { Transações esporádicas; } \\
\text { atitude distante e adversária }\end{array}$ & $\begin{array}{l}\text { Colaborativos; com } \\
\text { comprometimento e confiança } \\
\text { mútuas }\end{array}$ \\
\hline Horizonte Temporal & Curto prazo & Longo prazo \\
\hline $\begin{array}{l}\text { Configuração do } \\
\text { Fornecimento }\end{array}$ & $\begin{array}{l}\text { Maior base de fornecedores; } \\
\text { elevada integração vertical }\end{array}$ & $\begin{array}{l}\text { Menor base de fornecedores; baixa } \\
\text { integração vertical; fornecimento } \\
\text { de sistemas ou módulos }\end{array}$ \\
\hline $\begin{array}{l}\text { Número de Fornecedores por } \\
\text { Item }\end{array}$ & Sourcing múltiplo & Sourcing único ou duplo \\
\hline $\begin{array}{l}\text { Seleção e Avaliação de } \\
\text { Fornecedores }\end{array}$ & Principalmente preço & $\begin{array}{l}\text { Critérios multidimensionais, foco } \\
\text { em capacitação, adição de valor e } \\
\text { histórico de relacionamento }\end{array}$ \\
\hline Apoio Técnico & $\begin{array}{l}\text { Inexistente ou iniciativas de } \\
\text { caráter limitado }\end{array}$ & $\begin{array}{l}\text { Programas de desenvolvimento de } \\
\text { fornecedores }\end{array}$ \\
\hline $\begin{array}{l}\text { Comunicação e Troca de } \\
\text { Informações }\end{array}$ & Inexistente ou pouco freqüente & $\begin{array}{l}\text { Freqüente; política de portas } \\
\text { abertas }\end{array}$ \\
\hline $\begin{array}{l}\text { Envolvimento em Projeto e } \\
\text { Engenharia }\end{array}$ & Inexistente ou pouco freqüente & $\begin{array}{l}\text { Freqüente e desde o início do } \\
\text { processo de desenvolvimento de } \\
\text { novos produtos }\end{array}$ \\
\hline Práticas de Entrega & Baixa freqüência & Alta freqüência \\
\hline Atitude frente à Qualidade & $\begin{array}{l}\text { Menos rígida, inspeção após o } \\
\text { fato }\end{array}$ & $\begin{array}{l}\text { Mais estrita, controle de insumos e } \\
\text { processos, sistemas de avaliação }\end{array}$ \\
\hline Solução de Problemas & $\begin{array}{l}\text { Feedback limitado, baixo } \\
\text { compartilhamento de riscos e } \\
\text { benefícios, ajustes } \\
\text { independentes de mudanças na } \\
\text { demanda }\end{array}$ & $\begin{array}{l}\text { Feedback freqüente, elevado } \\
\text { compartilhamento de riscos e } \\
\text { benefícios, colaboração com vistas } \\
\text { a soluções conjuntas }\end{array}$ \\
\hline Ativos Especializados & Poucos ou não existentes & Muitos e significativos \\
\hline
\end{tabular}

\section{Metodologia}

A pesquisa relatada neste trabalho é parte de estudo mais abrangente, feito no período 1995-1996, sobre os relacionamentos entre compradores e fornecedores na indústria automotiva brasileira.

O método do estudo de caso foi considerado como o mais adequado para a realização da pesquisa, considerando-se os antecedentes e objetivos da investigação, em vista sobretudo do incipiente estado da pesquisa nas relações de forneci- 
mento no país e em países em desenvolvimento em geral, bem como do reduzido grau de compreensão e explicação do fenômeno estudado até aquela data. Segundo Yin (1993, p. 3), este "é o principal método de pesquisa quando o fenômeno em estudo não se distingue facilmente de seu contexto". Esse é claramente o caso do que se investiga neste trabalho, já que há interação complexa entre as organizações de negócios e entre estas e o ambiente. Além disso, também se caracteriza por ser um método "em que múltiplas fontes de evidência são utilizadas" (Yin, 1989 , p. 23).

Eisenhardt (1989) aponta as vantagens da pesquisa de estudos de casos na geração de teorias, sobretudo nos estágios iniciais de pesquisa sobre um assunto e para propiciar novas perspectivas em um tópico já pesquisado. A vantagem seria que, apesar de se basear em literatura anterior e em observação empírica, não se limita a elas, podendo valer-se também do insight do pesquisador, em abordagem especialmente útil para estudar processos de mudança. Ellram (1996, p. 115) aponta ainda que "excelentes oportunidades existem para se usar a metodologia de pesquisa de estudos de casos em muitas áreas da logística e de compras" [sendo esta ] "excelente para a construção de teorias, para oferecer explicações detalhadas das 'melhores práticas' e para propiciar maior entendimento dos dados coletados".

Os dados foram obtidos em entrevistas pessoais e em profundidade com executivos das empresas compradoras e fornecedoras. Pelo lado dos compradores, o estudo envolveu as 4 montadoras de automóveis de passeio que operam no país, todas subsidiárias de grandes fabricantes internacionais. Em duas das empresas, o entrevistado principal foi o próprio diretor de compras. Nas demais, o gerente de compras imediatamente abaixo do diretor. Foram entrevistados também executivos de outras áreas, entre as quais logística, qualidade, engenharia de produto e planejamento. Foram ao todo 14 os respondentes nesta etapa do trabalho de campo, que envolveu 15 horas de entrevistas, todas realizadas nos escritórios ou plantas das empresas, nos Estados de São Paulo (3) e Minas Gerais (1).

Pelo lado dos fornecedores, a pesquisa envolveu 9 fabricantes de autopeças de primeiro nível, isto é, empresas com relação direta de fornecimento às montadoras. A fim de minimizar as distorções na perspectiva dos fornecedores quanto ao relacionamento com os compradores, as empresas incluídas na pesquisa foram escolhidas entre aquelas premiadas pelas montadoras, sendo consideradas, portanto, fornecedoras de excelência. Ao todo, foram entrevistados 19 gerentes das firmas fornecedoras, entre os quais 8 dirigentes máximos e 3 diretores. Foram registradas no total 26 horas de entrevistas. As empresas fornecedoras pertenciam a diferentes segmentos da indústria: freios, forjados e fundidos, produtos de estamparia, retentores, juntas, mangueiras, filtros, rodas, sistemas elétricos e assentos; e esta- 
vam localizadas em dois Estados brasileiros, Minas Gerais (2) e São Paulo (7).

Apesar da riqueza das indicações obtidas na pesquisa e do potencial para o desenvolvimento da teoria na área de relacionamento entre compradores e fornecedores, a partir de suas conclusões, a escolha do método implica uma limitação do estudo, em termos da sua generalização para outras empresas e indústrias.

\section{A Perspectiva dos Fornecedores sobre os Avanços}

Todas as 9 empresas fornecedoras incluídas na pesquisa haviam adotado ou estavam em vias de adotar práticas de produção enxuta em suas operações internas. Considerou-se este aspecto muito significativo, à medida que suas percepções das exigências dos compradores com relação a práticas de fornecimento enxuto não se veriam influenciadas por possíveis dificuldades para seu atendimento.

As percepções gerais dos fornecedores com relação a seus relacionamentos com as montadoras de automóveis indicavam o que se segue.

. As atitudes das compradoras na negociação eram vistas como predominantemente intransigentes e do tipo ganha-perde, apesar de também poderem ser observadas melhorias nos níveis de comprometimento. Segundo um dos fornecedores entrevistados, "é mais uma relação de necessidade do que de parceria; diz que é um parceiro, mas alguém sempre perde". E, ainda, de acordo com outro, "esse negócio de parceria é uma piada mesmo. O que existe é que eles não o querem matar, mas vão fazer o possível para trabalhar no mínimo nível de preço; se você tiver mais $10 \%$, embora tenha fornecido por mais de dez anos um produto de ótima qualidade, mas apareceu um novinho [...] ele vira mais bonito e nos próximos [fornecimentos] a montadora lhe dá seis meses para você sair do negócio e acha que você tem de agradecer esses seis meses. Então não tem parceria, é muito pragmático".

. Havia uma tendência de horizontes mais longos nos relacionamentos e nos contratos, embora poucos fornecedores tivessem contratos propriamente ditos com as montadoras.

. Havia uma tendência mais acentuada na direção da relocalização dos fornecedores próximos às instalações das montadoras, assim como à contratação de sistemas ou módulos. 
. Havia uma tendência mais acentuada na direção de práticas de sourcing único, embora algumas montadoras ainda buscassem evitar maior dependência de determinados fornecedores.

- O preço ainda era o elemento mais importante nos processos de seleção de fornecedores por parte das montadoras.

. Estava sendo praticado maior apoio técnico por parte das montadoras.

- Havia mais troca de informações, embora isto não implicasse que a mesma fosse de boa qualidade, havendo muitas mudanças de última hora.

. Já estava havendo envolvimento mais precoce e mais intenso dos fornecedores no projeto de desenvolvimento de novos produtos, embora a prática se limitasse a apenas duas montadoras.

- Estavam sendo postas em prática exigências mais fortes e rígidas em termos de entregas freqüentes, em bases just-in-time.

. Estavam sendo postas em prática exigências mais rígidas com relação à qualidade.

. Havia uma melhoria em termos do feedback recebido, quanto ao desempenho. No entanto eram ainda limitadas as iniciativas, quanto à solução conjunta de problemas ou ao compartilhamento de riscos.

. Estava havendo uma necessidade mais forte de se contar com ativos especializados nos relacionamentos entre as compradoras e os fornecedores.

A maioria dos entrevistados nas empresas fornecedoras respondeu negativamente a perguntas diretas quanto à existência de diferenças significativas nas atitudes dos seus clientes na indústria automobilística brasileira; no entanto foi observada uma forte diferença na percepção dos fornecedores quanto aos avanços de seus relacionamentos com uma das montadoras, ao serem discutidos aspectos detalhados dos relacionamentos com base em cada uma das práticas/características identificadas no quadro conceitual.

\section{A Perspectiva dos Fornecedores quanto às Barreiras}

Diversas barreiras à adoção e ao sucesso das práticas de fornecimento enxuto foram identificadas pelos fornecedores. Da mesma maneira que na percepção das montadoras (Arkader, 1997), as barreiras mencionadas com maior freqüência 
diziam predominantemente respeito a fatores peculiares ao ambiente econômico e de negócios no Brasil. Estes são significativamente distintos dos que prevalecem nas economias desenvolvidas em inúmeros aspectos, como, por exemplo, a questão da estabilidade econômica, a situação das estradas e da infra-estrutura de transporte em geral, as condições de financiamento, as habilidades da mão-deobra etc. Essa observação ajuda a dar conta da literatura relativamente escassa sobre barreiras ambientais ao fornecimento enxuto, com a possível exceção de características estruturais da indústria tomada por contexto, como se comentou anteriormente.

Foram identificados dois conjuntos de barreiras ambientais relevantes aos avanços nas práticas de fornecimento enxuto. O primeiro corresponde àquelas de nível nacional, que afetam, portanto, a indústria como um todo, independentemente da localização da empresa. O outro seria pertinente a determinada região do país, influindo, assim, basicamente, sobre as firmas locais. Em ambos os conjuntos, as barreiras mais relevantes eram os problemas logísticos, que serviam de obstáculo ao desempenho de sistemas just-in-time e outras iniciativas colaborativas. Tais dificuldades incluíam estruturas e condições generalizadamente deficientes na área de transportes e comunicações. Outras barreiras encontradas em nível nacional seriam: as distorções fiscais, que funcionavam como empecilhos ao fornecimento de sistemas e módulos; as dificuldades na obtenção de financiamentos para os investimentos necessários ao atendimento às maiores exigências dos compradores; a inadequação da capacitação exigida de fornecedores de segundo e terceiro escalão; os baixos volumes, que levam à dificuldade de se alcançar escala apropriada, e problemas de câmbio, implicando baixa competitividade dos fornecedores locais com relação aos estrangeiros, devido à alegada sobrevalorização da moeda local.

As barreiras regionais afetavam principalmente a mais importante região industrial do país, o ABC, em São Paulo, onde se situa a maior parte das plantas de montadoras e fornecedores. Além dos problemas logísticos, agravados por excesso de tráfego, havia outros também adversos, tais como um maior custo da mãode-obra e os custos mais altos para instalação e expansão, devido a preços mais elevados dos terrenos e propriedades.

Foram identificadas diversas barreiras organizacionais com relação às empresas compradoras. As mais importantes diziam respeito ao excesso de burocracia e à natureza gigantesca das organizações das montadoras. Seriam esses problemas, mais ainda do que uma falta de intenção estratégica, que estariam obstando às melhorias em seu relacionamento com fornecedores. Os fornecedores identificaram uma séria falta de comunicação entre as áreas de compras, engenharia e manufatura dos clientes, que ia de encontro às práticas eminentemente integradoras 
exigidas pelo sistema de produção enxuta. Uma característica específica das barreiras organizacionais dizia respeito à perda, pelos compradores nos departamentos de compras das montadoras, do poder que anteriormente exerciam com relação à escolha dos fornecedores e à imposição das condições das transações. Em termos de aspectos organizacionais, é possível observar diferenças entre a perspectiva das empresas brasileiras e aquela dos fornecedores de países desenvolvidos, conforme encontradas na literatura. Como se discute em outro trabalho (Arkader e Fleury, 1998), os fornecedores brasileiros consideravam que seu relacionamento histórico com os fornecedores era cordial, havendo percepção de mudança nesta situação com a evolução das relações de fornecimento ao longo dos anos 90 .

\section{Conclusões: Implicações da Perspectiva dos Fornecedores}

Os resultados obtidos na pesquisa com relação à perspectiva dos compradores (Arkader, 1997) indicava uma visão consideravelmente mais otimista dos avanços em geral nos relacionamentos entre compradores e fornecedores na indústria automotiva brasileira. Segundo as montadoras, estaria havendo uma busca de parceria e melhoria nos relacionamentos. Os principais aspectos de avanço seriam quanto a atitudes de colaboração e apoio técnico, bem como de troca de informações e comunicação. Outras mudanças significativas nos relacionamentos se teriam dado quanto a uma atitude pró-ativa em face da qualidade e de maior disposição para a negociação, da busca de soluções conjuntas de problemas e dos critérios utilizados para a seleção de fornecedores, que não mais se limitariam a questões de preço.

Isto parece reforçar as observações na literatura com relação à tendência dos compradores a identificarem mais vantagens nos novos padrões de relacionamento e, em geral, à um hiato entre a retórica dos compradores e a realidade dos relacionamentos. Em oposição à perspectiva dos fornecedores, os compradores identificavam avanços em suas atitudes com relação à negociação com fornecedores, argumentavam escolher fornecedores antes com base em qualidade e serviço e histórico do relacionamento do que em preços e viam-se, de modo geral, como estando em busca de relacionamentos cooperativos e de parceria com seus fornecedores. Os fornecedores, por outro lado, identificaram avanços sobretudo em aspectos operacionais, tais como recebimento de apoio técnico e troca de informações; portanto a perspectiva dos fornecedores nos diz que os avanços com relação a relacionamentos de parceria não estavam sendo igualmente percebidos por ambos os lados. 
Também no caso de barreiras há diferenças entre a perspectiva dos fornecedores e aquela dos compradores. A ênfase no caso dos compradores recaía sobre problemas devidos a fatores ambientais, especialmente sistemas logísticos e fiscais desfavoráveis. Os fornecedores, por outro lado, embora identificassem praticamente as mesmas barreiras ambientais que os compradores, tendiam a dar ênfase equivalente a barreiras organizacionais dentro das montadoras, especialmente à existência de grupos funcionais de resistência e à perda de poder sofrida pelos compradores nos departamentos de compras, o que poria óbices a relacionamentos mais cooperativos.

Essas distintas percepções têm implicações para a explicação da trajetória dos relacionamentos entre compradores e fornecedores na indústria automobilística brasileira em passado recente. Pode-se ver que, segundo os fornecedores, haveria de fato um deslocamento na direção de uma melhoria nas práticas diretamente relacionadas à eficiência operacional. Entrega, qualidade e troca de informações e comunicação, envolvimento precoce de fornecedores em projeto e feedback de desempenho estão todas nesta categoria e, aqui, os fornecedores apontaram melhorias em seus relacionamentos com as montadoras. Segundo os princípios das operações enxutas, há redução de desperdício ao longo da cadeia de suprimentos, considerando-se que os principais fornecedores realizam suas entregas em uma base just-in-time (ou quase) e estão, eles mesmos, adotando cada vez mais intensamente sistemas enxutos de operações.

Ainda assim, segundo a perspectiva dos fornecedores, alguns elementos muito importantes do modelo de fornecimento enxuto estão ausentes de seu relacionamento com os compradores. A atitude das montadoras na negociação ainda é vista como inflexível e pouco cooperativa, o preço ainda é o principal elemento no processo de decisão de compras e os níveis de solução conjunta de problemas, especialmente com relação ao compartilhamento de riscos e benefícios, ainda são vistos como limitados.

A perspectiva dos fornecedores torna possível identificar uma lógica de eficiência subjacente nas novas práticas de fornecimento das empresas compradoras na indústria automobilística brasileira. Esta não parece estar sendo acompanhada, via de regra, por uma visão estratégica do papel dos fornecedores na perseguição aos objetivos da produção e do fornecimento enxutos. Além disso, soma-se a esta situação a existência de barreiras, tanto ambientais quanto organizacionais, que afetam a integração entre compradores e fornecedores. Estes parecem os elementos para uma compreensão mais aprofundada da trajetória e das possibilidades futuras dos relacionamentos entre compradores e fornecedores na indústria automobilística brasileira. 
ReFERENCIAS BibliográfICAS

ARKADER, R.

Relações de fornecimento no contexto da produção enxuta : um estudo na indústria automobilística brasileira. Rio de Janeiro, 1997. Tese (Doutorado em Administração) - Instituto de PósGraduação e Pesquisa em Administração, Universidade Federal do Rio de Janeiro.

ARKADER, R.;

FLEURY, P. F.

The evolution of buyer-supplier relationships in the automotive industry : perspectives in the brazilian context. In: $7 \mathrm{TH}$ INTERNATIONAL IPSERA CONFERENCE (1988: London). Proceedings... London : International Purchasing \& Supply Education \& Research Association, 1998.

KEARNEY, A. T. (Ed.).

Partnership or powerplay? London : A. T. Kearney, 1994.

BURNES, B.;

NEW, S.

Understanding supply chain improvement. European Journal Purchasing \& Supply Management, v. 2, n. 1, p. 2130, 1996.
DEPARTMENT OF TRADE AND INDUSTRY - DTI/ SOCIETY OF MOTOR MANUFACTURERS AND TRADERS LTD - SMMT.

A review of the relationships between vehicle manufacturers and suppliers. [S.1.], 1994.

DYER, J. H.;

OUCHI, W. G.

Japanese-style partnerships : giving companies a competitive edge. Sloan Management Review, p. 51-63, Fall 1993.

EISENHARDT, K. M.

Building theory from case study research. Academy of Management Review, v. 14, n. 4, p. 532-550, 1989.

ELLRAM, L. M.

The use of the case study methods in logistics research. Journal of Business Logistics, v. 17, n. 2, p. 93-138, 1996.

ELLRAM, L. M.;

EDIS, O. R. V.

A case study of successful partnering implementation. International Journal of Purchasing and Materials Management, p. 20-27, Fall 1996. 
HELPER, S.

How much has really changed between U.S. automakers and their suppliers? Sloan Management Review, p. 15-28, Summer 1991.

Three steps forward, two steps back in automotive supplier relations. Technovation, v. 14, n. 10, p. 633-640, 1994.

HINES, P.

Network sourcing in Japan. The International Journal of Logistics Management, v. 7, $\mathrm{n}$. 1, p. 13-28, 1996.

LAMMING, R.

Beyond partnership : strategies for innovation and lean supply. Englewood Cliffs, NJ : PrenticeHall, 1993.

\section{LEAVY, B.}

Two strategic perspectives on the buyer-supplier relationship. Production and Inventory Management Journal, p. 47-51, 2nd Quarter 1994.

LYONS, T. F.;

KRACHENBERG, A. R.;

HENKE JR., J. W.

Mixed motive marriages : what's next for buyer-supplier relations? Sloan Management Review, p. 29-36, Spring 1990.
MACBETH, D. K.;

FERGUSON, N.

Partnership sourcing : an integrated supply chain approach. London : Times/Pitman, 1994.

NISHIGUCHI, T.

Strategic dualism : an alternative in industrial societies. Oxford, 1989. Thesis (PhD) - Oxford University.

PURDY, L.;

ASTAD, U.;

SAFAYENI, F.

Perceived effectiveness of the automotive supplier evaluation process. International Journal of Operations \& Production Management, v. 14, n. 6, p. 91100, 1994.

SAKO, M.

Prices, quality and trust : interfirm relations in Britain \& Japan. Cambridge : Cambridge University Press, 1992.

STUART, F. I.;

MCCUTCHEON, D.

Problem sources in establishing strategic supplier alliances. International Journal of Purchasing and Materials Management, p. 03-09, Winter 1995 
TURNBULL, P.;

OLIVER, N.;

WILKINSON, B.

Buyer-supplier relations in the U.K. automotive industry : strategic implications of the japanese manufacturing model. Strategic Management Journal, v. 13, n. 2, p. 159-168, 1992.

TURNBULL, P. et al.

Winners and losers - the 'tiering' of component suppliers in the U.K. automotive industry. Journal of General
Management, v. 19, n. 1, p. 4863, Autumn 1993.

WOMACK, J. P.;

JONES, D. T.;

ROOS, D.

The machine that changed the world. New York : Harper Perennial, 1991.

YIN, R. K.

Case study research : design and methods. London: Sage, 1989.

Applications of case study research. London: Sage, 1993. 